\title{
CHEAF (Child Health and Education Assessment Forum): a multi-disciplinary powwow for children
}

\author{
Christine Williams, Barry Wright and Rob Smith
}

It has been recommended that child and adolescent mental health services operate on four tiers (NHS Health Advisory Service, 1995). Tier three represents specialist teams, where professionals work together to provide specialist services. Since additional resources have not been forthcoming to support such developments, existing teams frequently restructure themselves in order to operate in this way. One way of rationalising existing resources effectively is to establish interagency links so that multi-disciplinary working is not limited by professional boundaries. This can occur across as well as within teams.

Parents or carers of children with complex needs often find they are seeing professionals from different services. They may hear different formulations of the child's problem and may receive different suggestions for management. Multi-disciplinary teamwork is well supported. particularly with respect to child protection work (Department of Health, 1995), and such approaches have also been spawned by children with complex needs which cross child mental health and social work boundaries (Wheeler et al, 1998). It is now relatively common for paediatric teams to work closely with child mental health teams (Bingley et al, 1980; Dungar et al, 1986). The multi-disciplinary assessment of children with conditions such as attention deficit hyperactive disorder (ADHD) is well recognised (Voeller. 1991) and multi-agency assessment initiatives have recently been established for other difficulties (Holt \& Connor, 1998; Ward \& Keen, 1998). Some studies have found that children with health problems who require educational support or intervention as part of their treatment may not get it because of poor liaison (Jensen et al, 1989).

\section{Establishing the team}

Recognising that there are several problems which cross the boundaries between child health. child mental health, school health and education authority services a Child Health and Education Assessment Forum (CHEAF) has been developed between York National Health Service Trust and the education authority in York. It includes a child psychiatrist, a clinical psychologist, a paediatrician, and an educational psychologist, a community psychiatric nurse and a school doctor.

The growing number of referrals of children for assessment for possible ADHD made it increasingly important that all of the professionals in health and education involved in the assessment and service provision for children should try to reach a joint understanding of the problem.

A multi-agency meeting was set up after a conference on ADHD, and this raised a number of issues. Different professions had quite diverse views in their understanding of $A D H D$. There was a lack of clarity about various professional practices and debate took place about the best available interventions and who should deliver them. There were some emotive discussions about the use of medication. Through the process of debate the group gradually began to reach a common understanding and relationships developed between professionals with increasing trust and collaboration. An ADHD clinic was rejected as an idea because the vast majority of referrals were being dealt with well by existing services. There was a recognition that difficulties existed in the more complex cases where the clinician was uncertain or the parents were requesting a second opinion. Discussions broadened out to include children with a range of problems where education was impacted upon by paediatric or child mental health problems. These included children who were terminally ill or children with chronic fatigue syndrome or any other chronic physical/psychological illnesses affecting health, social and educational development. These were often complex and required high levels of cooperation between health and 
education services. It was primarily this recognition which led to the establishment of CHEAF.

\section{The operation of CHEAF}

The forum only discusses children with particularly complex problems requiring a high degree of cooperation and collaboration. Referrals are taken from paediatricians, members of the child and adolescent mental health team, school health services and education services following discussion with one of the CHEAF team members. Before the child is discussed, the nature of this service is explained to the parents and their informed consent to share information sought. A list of children to be discussed is circulated to each member of the team several weeks in advance. Notes, minutes and other administration tasks are performed by one of the team. CHEAF meets for two hours every two months. Children are not seen at this time. Children are discussed only after full assessment by one of the team members. Other professionals may have seen the children and their families at various times in the past for which reports or letters are made available.

On average three new cases are discussed and three further cases reviewed at each meeting. At the initial discussion decisions are taken about what further information needs to be collated and what further assessments required. Such assessments may be by a speech and language therapist, an occupational therapist, an educational psychologist, a psychiatrist, a clinical psychologist, a community psychiatric nurse, a paediatrician, a school doctor or another professional such as a teacher making systematic classroom observations. These assessments are arranged and reports requested by a certain date. The keyworker then communicates this information to the parents and the referrer and the child's name is placed on the list for discussion at the next meeting. Once all assessments and information are to hand then further discussion takes place about how best to conceptualise and formulate the child's problems, what diagnoses if any should be made, and then discussion moves on to what interventions may be helpful, who should deliver them and what follow-up is necessary and by whom. The keyworker continues to keep parents informed following each meeting. Interestingly, some parents who had initially declined direct psychological or psychiatric involvement gave their consent readily to the indirect involvement of mental health professionals in CHEAF.

\section{Referrals}

Between October 1996 and February 1998, the CHEAF team have discussed 15 children. Twelve were referred for discussion concerning ADHD and three concerning chronic fatigue syndrome. This represents approximately $10 \%$ of ADHD referrals to the Child and Adolescent Psychology and Psychiatry Team. Reasons for taking them to CHEAF varied. In some instances it was because they were complex situations with difficulties that impacted across child mental health, child health and education where inter-agency, interdisciplinary cooperation was essential and easily facilitated through CHEAF. In some instances referrals were made because there were strongly held views by parents which ran contrary to initial assessment findings from a clinician, so that CHEAF effectively provided a second opinion by other clinicians and more formal assessment through educational psychology services. In some there were comorbid disorders or learning difficulties. Of the 12 'ADHD' children, three are now taking methylphenidate and are supported by health and education services, who continue to offer behavioural advice. Six were not given a diagnosis of ADHD but continue to be supported by health and education services. Three are still being assessed. The three chronic fatigue syndrome children all needed follow-up by a paediatrician, ongoing cognitive therapy and graded rehabilitation coordinated by a child mental health team member in a family setting. Support from school was necessary as they re-integrated with various elements of special provision which was flexible and changeable. Cooperation and the sharing of information between professionals was essential in order for all those involved to know what the others were doing and saying, as well as reaching a common understanding of the difficulties with coordination of interventions. One of the three children is now fully back to school, one in a pupil referral unit and the other is gradually increasing time spent in his school.

\section{Conclusion}

CHEAF is seen to provide a discrete, integrated, accessible service. It provides for children with complex needs, particularly where a high level of common understanding and cooperation is required between trust services and education services.

\section{Acknowledgement}

We would like to thank Ian Partridge for helpful comments on an early draft of this paper.

\section{References}

Bingley, L., Leonard, J., Hensman, S., et al (1980) The comprehensive management of children on a paediatric ward: a family approach. Archives of Disease in Childhood, 55, 555-561. 
Department OF HEalth (WELSH OfFice) (1995) Child Protection: Clarification of Arrangements Between the NHS and Other Agencies. London: HMSO.

Dungar, D., PrITchard, J., Hensman, S., et al (1986) The investigation of atypical psychosomatic illness: a team approach to diagnosis. Clinical Pediatrics, 25. 341-344.

HOLT, K. M. \& CONNOR. S. A. (1998) Multiagency interdisciplinary assessment teams: do they work? Proceedings of the Royal College of Paediatrics and Child Health Annual Spring Meeting, 2, 89.

Jensen, P. S., XenAKIS, S. N., SherVetTe. R. E., et al (1989) Diagnosis and treatment of attention deficit disorder in two general hospital clinics. Hospital and Community Psychiatry, 40, 708-712.

NHS HEALTH ADVISORY SERVICE (1995) Together We Stand: The Commissioning. Role and Management of Child and Adolescent Mental Health Services (eds R. Williams \& G. Richardson). London: HMSO.

VOELLER, K. K. (1991) Clinical management of attention deficit hyperactivity disorder. Journal of Child Neurology, 6 (suppl.), S51-S67.
WARD, S. \& KEEN, D. (1998) Using a child health information system to describe a district population of children with autistic spectrum disorder. Proceedings of the Royal College of Paediatrics and Child Health Annual Spring Meeting, 2, 89

WHEELER, J., BONE, D. \& SMITH, J. (1998) Whole day assessments: a team approach to complex multiproblem families. Clinical Child Psychology and Psychiatry. 3, 169-181.

*Christine Williams, Clinical Psychologist, Barry Wright, Consultant Child Psychiatrist, and Robert Smith, Consultant Paediatrician, Lime Trees, Child, Adolescent and Family Unit, 31 Shipton Road, York YO30 5RF

*Correspondence

\section{Mental Health and Growing Up Factsheets Factsheets for parents, teachers and young people}

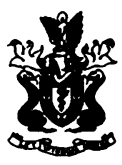

This series of 21 factsheets aims to provide practical, up-to-date information about the emotional and psychiatric disorders which affect children and young people.

For parents and teachers:

Sleep problems in childhood and adolescence $\bullet$ Discipline and your child $\bullet$ Children who soil and wet themselves $\bullet$ Children who do not go to school $\bullet$ The emotional cost of bullying $\bullet$ The child with general learning disability $\bullet$ Specific learning difficulties $\bullet$ Behaviour problems and conduct disorder $\bullet$ Traumatic stress in children: how parents can help $\bullet$ Child abuse and neglect: the emotional effects $\bullet$ Death in the family: helping children to cope $\bullet$ Parental mental illness: the problems for a child $\bullet$ Hyperactivity and attention deficit problems $\bullet$ Severe mental disorders in children and young people $\bullet$ Suicide and self-harm in young people $\bullet$ Child and adolescent psychiatrists: how they can help $\bullet$ The impact on children and adolescents of divorce or separation of parents

For young people:

- Coping with stress $\bullet$ Worries about weight $\bullet$ Drug and alcohol misuse $\bullet$ Depression in children and young people

1997, A4 wallet with inserts, $£ 7.50$

Available from Book Sales, Royal College of Psychiotrists, 17 Belgrave Square, London SWIX 8PG Tel +44 (0) 1712352351 (extension 146), Fax +44 (0) 1712451231 http://www.rcpsych.oc.uk 